\title{
Cohort Profile: The China Metal-Exposed Workers Cohort Study (Jinchang Cohort)
}

\author{
Yana Bai, ${ }^{1 *}$ Aimin Yang, ${ }^{1,3}$ Huangquan $\mathrm{Pu}^{2}{ }^{2}$ Min Dai, ${ }^{4}$ Ning Cheng, ${ }^{5}$ \\ Jiao Ding, ${ }^{2}$ Juansheng $\mathrm{Li}^{1}{ }^{1}$ Haiyan $\mathrm{Li}^{2}{ }^{2}$ Xiaobin $\mathrm{Hu},{ }^{1}$ Xiaowei Ren, ${ }^{1}$ \\ Jie $\mathrm{He}^{4}$ and Tongzhang Zheng ${ }^{3}$
}

${ }^{1}$ Institute of Epidemiology and Statistics, School of Public Health, and Center for Cancer Prevent and Treatment, Lanzhou University, Lanzhou, Gansu, China, 'Workers' Hospital of Jinchuan Group Co., Jinchang, Gansu, China, ${ }^{3}$ Department of Epidemiology, Brown University, Providence, RI, USA, ${ }^{4}$ Cancer Institute and Hospital, Chinese Academy of Medical Sciences, Beijing, China and ${ }^{5}$ Center of Medical Laboratory, Lanzhou University, Lanzhou, Gansu, China

${ }^{*}$ Corresponding author. Yana Bai, Institute of Epidemiology and Statistics, School of Public Health, Lanzhou University, Lanzhou, Gansu, China. E-mail: baiyana@|zu.edu.cn

Accepted 13 July 2016

\section{Why was the cohort set up?}

Chinahas experienced rapid socioeconomic and epidemiological changes over the past 30 years, which led to a vast increase in energy consumption and serious environment pollution. Among the different types of pollution, heavy metal pollution becomes one of the major environmental concerns in China. ${ }^{1}$ China becomes the largest producer and consumer of metals in the world, with increasing pollution from metals due to industrialization. ${ }^{2}$ Metal mining and production industries are among the largest sources of environmental pollution. A large amount of metals have been released into the environment due to mineral processing activities, and have significant health implications for occupational workers and general populations resulting from environmental pollution.

Exposure to metal and metal compounds can result in a variety of adverse effects on human health, although we do not fully understand their impact. ${ }^{3-5}$ Some heavy metals, such as arsenic (As), cadmium (Cd), chromium (Cr) and nickel $(\mathrm{Ni})$, are significant toxicants and carcinogens, ${ }^{6}$ which are designated as carcinogenic to humans (Group 1) by the International Agency for Research on Cancer. ${ }^{7}$ Exposure to As, $\mathrm{Cd}$ and $\mathrm{Ni}$ may also adversely affect chronic disease such as obesity, diabetes and metabolic syndrome. ${ }^{8}$ Additionally, environmental chemicals including heavy metals could challenge the dynamic interplay with genetic, nutritional and physical activity factors, which alter public health risk of chronic diseases, especially in China with its rapid socioeconomic growth and urbanization. Millions of workers have been occupationally exposed to and will continue to be exposed to the toxic working environment, even though China has taken the steps to improve pollution controls in the toxic metal industry during recent years. Thus, targeting prospective research studies in occupationally exposed populations, particularly in metal-exposed workers, is a cost-effective approach to evaluate the potential adverse health effects of heavy metal. ${ }^{9}$ However, no large prospective cohort has been established to study the relationships between multiple metal exposures and human health.

The Jinchuan Nonferrous Metals Corporation (JNMC) is a large mining group with about 45000 workers, which is engaged in mining, concentrating, metallurgy, chemical engineering and deep processing. It is located in Jinchang city, Gansu province. The primary focus of the company is on the smelting and processing of nickel, copper and cobalt 
as well as the chemical processing of materials. It has become the third largest nickel and second largest cobalt manufacturing enterprise in the world, and more than $90 \%$ of the nickel group metals in China come from there. ${ }^{10}$ Workers in the JNMC are routinely exposed to nickel as well as several other contaminants, including dust, particulate matter and gaseous pollutants, cobalt and chromium. Many of these substances are considered as definite or possible carcinogens. ${ }^{7}$ Since 2011, the JNMC has required a biannual medical examination for all of its employees. On this basis we established the China MetalExposed Workers Cohort Study (Jinchang Cohort Study) with a cross-sectional baseline survey from June 2011 to December 2013. Thus, the Jinchang Cohort Study provides an opportunity to evaluate a series of health effects of multiple metal exposures.

The Jinchang Cohort Study is a collaborative study between Lanzhou University, Workers' Hospital of JNMC, National Cancer Center of China and Brown University. The study obtained approvals from the Public Health School of Lanzhou University and written informed consent from the participants.

\section{What does the study cover?}

The objective of this study is to create a large cohort which includes comprehensive epidemiological and biological data to understand environmental toxicity, especially from metal exposure, and to understand the associations of exposure to metal with risk of cancer and other diseases. The main contents and specific aims of this study include: (i) the retrospective cohort study with the purpose to assess the status of overall mortality and cause-specific mortality among occupational workers of the JNMC between 2001 and 2010; (ii) the establishment of the Jinchang Cohort Study which includes four parts of cross-sectional baseline survey (in-person interviews, physical examination, clinical laboratory-based tests and biosample collection) with purposes to ascertain exposed and non-exposed workers and prevalent cases for future calculation of incidence. Figure 1 shows the design of the Jinchang Cohort Study.

\section{Who is in the cohort?}

There are 44947 workers employed at the JNMC, including both in-service workers and retirees. All workers have been since 2011 eligible for a medical examination every 2 years, which includes in-person interviews, comprehensive physical examinations, laboratory tests and biosample collection. Only those who participated in the medical examination were eligible to enter the cohort. The initial medical examination began in June 2011 and ended in December 2013. Of 44947 subjects, 42122 (93.7\%) were included in the cohort and $2825(6.3 \%)$ were excluded because they had not completed the full medical examination. Thus, a sample of 42122 workers $(61.7 \%$ men, $38.3 \%$ female) constituted this cohort. Table 1 showed the comparison of the socio-demographic characteristics between the eligible workers and non-eligible workers.

\section{How often will they be followed up?}

The JNMC provides a free medical examination for all of its workers every 2 years. This medical benefit provides a great mechanism facilitating the follow-up process. Worker's Hospital of the JNMC is the largest medical care facility for all employees. All the results from medical examinations were directly entered into the computer system are available for the study. Each participant has a unique medical examination number and ID, making it easy for the follow-up process. Baseline survey of the Jinchang Cohort Study was performed between June 2011 and December 2013. Furthermore, the first follow-up of the cohort was started immediately after the baseline survey. By 7 December 2015, 37040 (87.9\%) participants completed the four parts of medical examination, of whom

\section{Jinchang Cohort}

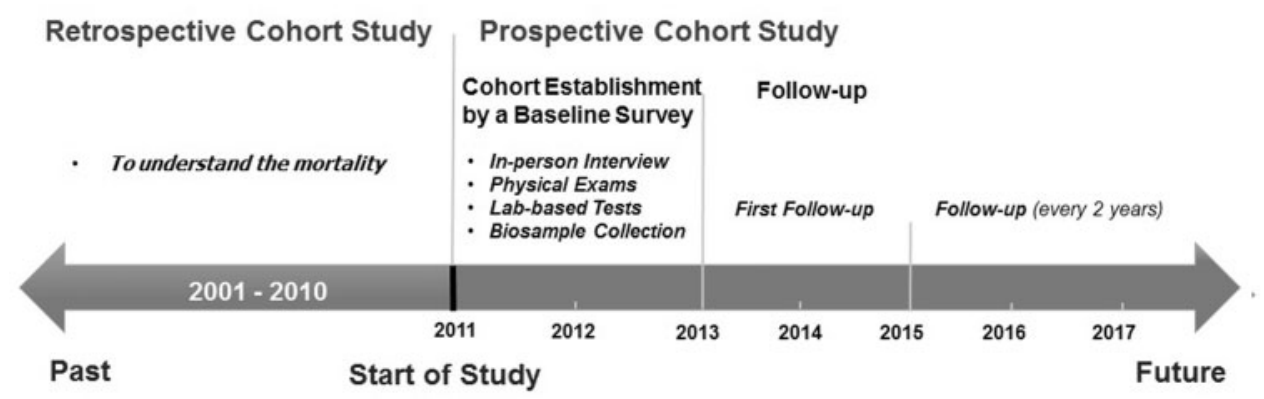

Figure 1. Study design of the China metal exposed workers cohort Study (Jinchang Cohort). 
Table 1. Comparison of the socio-demographic characteristics between the eligible and non-eligible workers in the Jinchang Cohort Study

\begin{tabular}{|c|c|c|c|}
\hline Variables & $\begin{array}{l}\text { Eligible } \\
\text { workers } \\
(42122)\end{array}$ & $\begin{array}{l}\text { Non-eligible } \\
\text { workers } \\
(2825)\end{array}$ & $P$-value \\
\hline \multicolumn{4}{|l|}{ Sex, $n(\%)$} \\
\hline Male & $26008(61.7)$ & $1311(46.4)$ & \multirow[t]{2}{*}{0.001} \\
\hline Female & $16114(38.3)$ & $1514(53.6)$ & \\
\hline \multicolumn{4}{|l|}{ Age (years), $n(\%)$} \\
\hline $20-29$ & $4771(11.3)$ & $201(7.1)$ & \multirow[t]{6}{*}{0.001} \\
\hline $30-39$ & $7433(17.7)$ & $237(8.4)$ & \\
\hline $40-49$ & $16127(38.3)$ & $933(33)$ & \\
\hline $50-59$ & $5704(13.5)$ & $462(16.4)$ & \\
\hline $60-69$ & $5412(12.9)$ & $473(16.7)$ & \\
\hline$\geq 70$ & $2675(6.4)$ & $519(18.4)$ & \\
\hline \multicolumn{4}{|l|}{ Race, $n(\%)$} \\
\hline Han Chinese & $40887(97.1)$ & $2747(97.2)$ & \multirow[t]{3}{*}{0.420} \\
\hline Hui Chinese & $691(1.6)$ & $38(1.4)$ & \\
\hline Other ethnic groups & $544(1.3)$ & $40(1.4)$ & \\
\hline \multicolumn{4}{|l|}{ Education, $n(\%)$} \\
\hline Primary school or illiteracy & $5368(12.7)$ & $521(18.4)$ & \multirow[t]{4}{*}{0.001} \\
\hline Middle school & $10244(24.3)$ & $814(28.8)$ & \\
\hline High school & $11409(27.1)$ & $743(26.3)$ & \\
\hline University or higher & $15101(35.9)$ & $747(26.4)$ & \\
\hline \multicolumn{4}{|l|}{ Marital status, n (\%) } \\
\hline Never married & $3726(8.9)$ & $154(5.5)$ & \multirow[t]{5}{*}{0.001} \\
\hline Married & $35243(83.7)$ & $2328(82.4)$ & \\
\hline Remarried & $472(1.1)$ & $33(1.2)$ & \\
\hline Divorced/widowed & $1289(3.1)$ & $96(3.4)$ & \\
\hline Widowed & $1392(3.3)$ & $214(7.6)$ & \\
\hline
\end{tabular}

495 were newly recruited workers. The first follow-up finished at the end of March 2016. The next follow-ups for the cohort will be held in 2016-17 and 2018-19.

\section{What has been measured?}

For the retrospective phase of the mortality cohort study, we collected the annual number of workers and data on exposures, deaths and causes of death between 2001 and 2010. The annual number of workers had been collected from the Department of Human Resources and Center of Retirees Management of the JNMC. We collected occupational exposure, demographic, mortality and employment information from different departments of the JNMC. The qualitative exposures data included processes, tasks and activities where workers might be exposed to metals, likely levels of exposure, existing control measures, job location and duration of employment in a different workplace. The causes of death were based on death certificates which came from the Worker's Hospital, Medical Insurance Center, Public Security Bureau and labour union of secondary units. The causes of death were coded according to the International Classification of Diseases, Revision 10 (ICD-10). Then we calculated the population-time, standardized mortality ratios (SMRs) to obtain information on the overall mortality and the cause of mortality for workers in the JNMC.

We established this prospective cohort with a crosssectional baseline survey which included four parts of a comprehensive medical examinations: in-person interview, comprehensive physical examination, clinical laboratorybased tests and biosample collection. Table 2 summarizes the broad categories of measurements at baseline and the first follow-up.

The in-person interview was conducted at the hospital by trained interviewers through a standardized and structured questionnaire. We investigated a wide range of demographic, socioeconomic, lifestyle, dietary, occupational exposure, self-reported medical history, family history of diseases and female reproductive history, and stress and psychological status. The comprehensive physical examinations were performed by clinicians at the Workers' Hospital of the JNMC immediately after the completion of the in-person interview, using standard protocols and techniques. ${ }^{11}$ These included anthropometric characteristics (weight, height and blood pressure), hearing, vision, and imaging examinations (electrocardiograms, ultrasonic B and X-ray examinations). Blood samples were collected by clinicians during the morning after the examinees had fasted overnight. All participants provided blood samples; $20 \%$ of participants provided urine samples; $6 \mathrm{ml}$ of fasting blood sample was collected from each participant and part of the sample was stored for future use. Part of the blood samples was also used for the subsequent laboratory tests by a clinical chemistry automatic analyzer (Hitachi 7600-020, Kyoto, Japan) including: haematological traits, hepatic and renal function, lipids, fasting glucose and electrolytes. Further samples in the form of plasma and serum have been cryopreserved at $-80^{\circ} \mathrm{C}$. The samples in the form of haemocytes, blood clots and urine samples have been cryopreserved at $-40^{\circ} \mathrm{C}$. All the cryopreserved blood samples and urine samples were stored in 1.8-ml cryogenic tubes for future genetic and gene-environment interaction study.

The interview data were entered by trained investigators into the computer twice, using EpiData software. The data of physical examinations and clinical laboratory-based tests were derived from the Hospital Biochemical Data Management System. All bio samples were tracked though an electronic database. We used the SAS software to establish and manage the Jinchang cohort database which is a multiple database (including interview dataset, biochemical dataset and biosample dataset). The database and 
Table 2. Summary of measurements at baseline and follow-up in the Jinchang Cohort Study

\begin{tabular}{|c|c|}
\hline Medical examination & Measurements \\
\hline \multirow[t]{8}{*}{ In-person interview } & $\begin{array}{l}\text { Demographics and socioeconomic Information: sex, age, nationality, date of birth, education, marital status, } \\
\text { household income }\end{array}$ \\
\hline & Lifestyle: tobacco smoking, alcohol drinking, tea drinking, physical exercise \\
\hline & $\begin{array}{l}\text { Occupational exposures: type of work, job shop, the environment, deleterious substance contact history, dur- } \\
\text { ation of employment, measurement of urinary metal concentrations }\end{array}$ \\
\hline & Dietary: ${ }^{\mathrm{a}}$ vegetables, fruits, meat, milk, egg and bean consumption \\
\hline & $\begin{array}{l}\text { Self-reported medical history: cancer, respiratory diseases, cardiovascular diseases, digestive system diseases, } \\
\text { urogenital diseases, diabetes, skin allergic disease and occupational diseases }\end{array}$ \\
\hline & $\begin{array}{l}\text { Family history of diseases: heart disease, stroke, high blood pressure or diabetes, chronic obstructive pulmonary } \\
\text { disease, cancer }\end{array}$ \\
\hline & $\begin{array}{l}\text { Reproductive history: age at menarche, age at menopause, parity, breastfeeding, contraception, hormone re- } \\
\text { placement therapy }\end{array}$ \\
\hline & Stress and psychological status: ${ }^{a}$ psychological morbidity, stress, optimism, social isolation \\
\hline Physical examination & $\begin{array}{l}\text { Anthropometric measures: weight, height, body mass index (BMI), blood pressure, hearing, vision, imaging } \\
\text { (electrocardiograms, ultrasonic B, X-ray examination) }\end{array}$ \\
\hline \multirow[t]{5}{*}{ Clinical lab-based tests } & Haematological traits: white blood cells (WBC), red blood cells (RBC), platelet count (PLT), haemoglobin etc. \\
\hline & $\begin{array}{l}\text { Hepatic function: alanine aminotransferase (ALT), aspartate aminotransferase (AST), alkaline phosphatase } \\
\text { (ALP), gamma glutamyltransferase (GGT) etc. }\end{array}$ \\
\hline & $\begin{array}{l}\text { Lipids: total cholesterol (TC), triglycerides (TG), high- and low-density cholesterol lipoprotein (HDL-C, } \\
\text { LDL-C), fasting plasma glucose (FPG) }\end{array}$ \\
\hline & Renal function: blood urea nitrogen (BUN), creatinine, total bile acid (TAB) \\
\hline & Electrolytes: $\mathrm{K}, \mathrm{Na}, \mathrm{Cl}, \mathrm{Ca}, \mathrm{P}, \mathrm{Mg}$ \\
\hline Biosample collection & Blood (plasma, serum, haemocytes, blood clotting) and urine samples \\
\hline
\end{tabular}

${ }^{a}$ Not addressed at baseline survey.

blood samples were stored at the Public Health School of Lanzhou University.

\section{What has it found? Key findings and publications}

For the retrospective mortality analysis of the cohort, a total of 44482 workers with 432526 person-years were observed between 2001 and 2010. There were 2576 who workers died during this 10 -year period. The detailed results have been published. ${ }^{12,13}$ Briefly, the all-cause mortality was decreased in all workers compared with the general population of Gansu province $(\mathrm{SMR}=0.5,95 \%$ CI: 0.5-0.6). However, analyses examining cause-specific mortality revealed an increase in mortality from bronchogenic carcinoma and lung cancer $(\mathrm{SMR}=2.1,95 \% \mathrm{CI}$ : 1.8-2.3), cor pulmonale ( $\mathrm{SMR}=4.1,95 \% \mathrm{CI}$ : 3.3-5.0), silicosis (SMR $=13.6,95 \%$ CI: 11.9-15.5) and type 2 diabetes (T2D) $(\mathrm{SMR}=1.5,95 \% \mathrm{CI}: 1.2-1.8)$. The results supported previous evidence, hinting at association of exposure to nickel and other metals with lung cancer, ${ }^{14}$ and also indicating that occupational exposure to metal may be associated with mortality from other non-carcinogenic health effects. However, the evidence of relationship between metal exposure and the risk of chronic diseases is scarce, ${ }^{9}$ thus needing to be further studied.
Table 3 shows the baseline characteristics of participants. Among 42122 workers, 61.7\% were male workers and $38.3 \%$ were female workers. The mean age was 46.4 years (46.8 years for males, 45.8 years for females). Behavioural risk factors at baseline were highly prevalent; specifically among male workers, 58.9\% were current smokers and $30.2 \%$ were current drinkers. The mean height was $167.9 \mathrm{~cm}(171.7 \mathrm{~cm}$ for men, 161.9 for women). The mean weight was $66.6 \mathrm{~kg}(71.1 \mathrm{~kg}$ for men, $59.4 \mathrm{~kg}$ for women). The mean SBP and DBP were $123.4 \mathrm{mmHg}$ and $78.7 \mathrm{mmHg}$, respectively. Among the participants, the prevalence of overweight and obesity was $27.9 \%$ and $3.2 \%$, respectively. Table 3 also presents the prevalence of hypertension $(28.9 \%)$, T2D (7.5\%), hyperlipidaemia $(46.4 \%)$ and other self-reported diseases. The mean values and distributions of haematological traits, hepatic and renal function and lipids are shown in Table 4.

Some of results based on the baseline data of the cohort have also been published. ${ }^{15-22}$ The prevalence of metabolic syndrome (MetS), overweight and hyperlipidaemia was high in the occupational workers of the cohort, in particular among male workers. ${ }^{20}$ Occupations associated with higher levels of metal exposures were related to increased risk of T2D among those workers. ${ }^{19}$ The strongest risk for T2D was observed among the smelting/refining male workers who also consumed the highest amount of tobacco 
Table 3. The baseline characteristics of participants in the Jinchang Cohort Study

\begin{tabular}{|c|c|c|c|}
\hline Variables & Male, $n(\%)$ & Female, $n(\%)$ & Total, $n(\%)$ \\
\hline Sex & 26008 (61.7) & 16114 & $42122(100)$ \\
\hline Age, mean $\pm \mathrm{SD}$, (years) & $46.8 \pm 14.1$ & $45.8 \pm 11.8$ & $46.4 \pm 13.3$ \\
\hline \multicolumn{4}{|c|}{ Behavioural risk factors } \\
\hline Current smokers ${ }^{\mathrm{a}}$ & $15323(58.9)$ & $218(1.4)$ & $15541(36.9)$ \\
\hline Former smokers & $3556(13.7)$ & $48(0.3)$ & $3604(8.6)$ \\
\hline Current drinkers ${ }^{\mathrm{b}}$ & $7841(30.2)$ & $342(2.1)$ & $8183(19.4)$ \\
\hline Former drinkers & $1670(6.4)$ & $38(0.2)$ & $1708(4.1)$ \\
\hline Height $(\mathrm{cm})$ & $171.7(6.2)$ & $161.9(5.9)$ & $167.9(7.7)$ \\
\hline Weight $(\mathrm{kg})$ & $71.1(10.4)$ & $59.4(8.9)$ & $66.6(11.3)$ \\
\hline $\begin{array}{l}\text { Systolic blood pressure } \\
\qquad(\mathrm{SBP}),(\mathrm{mmHg})\end{array}$ & $126.3 \pm 19.1$ & $118.7 \pm 20.0$ & $123.4 \pm 19.8$ \\
\hline $\begin{array}{l}\text { Diastolic blood } \\
\text { pressure } \\
(\mathrm{DBP}),(\mathrm{mmHg})\end{array}$ & $80.0 \pm 12.6$ & $76.5 \pm 12.0$ & $78.7 \pm 12.5$ \\
\hline \multicolumn{4}{|l|}{ BMI } \\
\hline Normal $(<25)$ & $16411(63.1)$ & $12646(78.5)$ & $29057(69.0)$ \\
\hline Overweight (25-29.9) & $8709(33.5)$ & $3024(18.8)$ & $11733(27.9)$ \\
\hline Obesity $(\geq 30)$ & $888(3.4)$ & $444(2.8)$ & $1332(3.2)$ \\
\hline \multicolumn{4}{|l|}{ Occupation } \\
\hline $\begin{array}{l}\text { Management and } \\
\text { services }\end{array}$ & $6099(23.5)$ & $3915(24.3)$ & $10014(23.8)$ \\
\hline $\begin{array}{c}\text { Chemical/metal } \\
\text { production }\end{array}$ & $6614(25.5)$ & $8000(49.6)$ & $14614(34.7)$ \\
\hline Mining/smelting & $13295(51.1)$ & $4199(26.1)$ & $17494(41.5)$ \\
\hline Hypertension $^{c}$ & $8504(32.7)$ & $3658(22.7)$ & $12162(28.9)$ \\
\hline Type 2 diabetes ${ }^{\mathrm{d}}$ & $2329(9.0)$ & $832(5.2)$ & $3161(7.5)$ \\
\hline Hyperlipidaemia $^{\mathrm{e}}$ & $14112(54.3)$ & $5448(33.8)$ & $19560(46.4)$ \\
\hline \multicolumn{4}{|l|}{ Self-reported diseases } \\
\hline Chronic rhinitis & $2698(10.4)$ & $2019(12.5)$ & $4717(11.2)$ \\
\hline Gall stones & $2082(8.0)$ & $2155(13.4)$ & $4237(10.1)$ \\
\hline Fatty liver & $3203(12.3)$ & $1060(6.6)$ & $4263(10.1)$ \\
\hline Cholecystitis & $1981(7.6)$ & $2080(12.9)$ & $4061(9.6)$ \\
\hline $\begin{array}{l}\text { Protrusion of } \\
\quad \text { intervertebral disc }\end{array}$ & $1986(7.6)$ & $1830(11.4)$ & $3816(9.1)$ \\
\hline Chronic sore throat & $1757(6.8)$ & $1480(9.2)$ & $3237(7.7)$ \\
\hline Uterine fibroids & - & $1498(11.1)$ & - \\
\hline Chronic gastritis & $1628(6.3)$ & $1090(6.8)$ & $2718(6.5)$ \\
\hline
\end{tabular}

SD, standard deviation.

${ }^{a}$ Current smokers were defined as those who smoked at least one cigarette per day in the past 6 months.

${ }^{\mathrm{b}}$ Current drinkers were those who drank hard liquor, beer or wine at least once per week during the past 6 months.

${ }^{c}$ Hypertension was defined as systolic blood pressure $\geq 140 \mathrm{mmHg}$ or diastolic $\geq 90 \mathrm{mmHg}$, or self-reported treatment for hypertension.

${ }^{\mathrm{d}}$ Type 2 diabetes was recorded if participants were on anti-diabetic medications or if their baseline fasting plasma glucose(FPG) was high $(\geq 7.0 \mathrm{mmol} / \mathrm{l})$ at the time of cohort entry.

${ }^{\mathrm{e}}$ Hyperlipidaemia were defined as: TG $\geq 1.70 \mathrm{mmol} / \mathrm{l}(150 \mathrm{mg} / \mathrm{dl})$, or HDL$\mathrm{C}<0.9 \mathrm{mmol} / \mathrm{l}(35 \mathrm{mg} / \mathrm{dl})$ in men and $<1.0 \mathrm{mmol} / \mathrm{l}(39 \mathrm{mg} / \mathrm{dl})$ in women.

or alcohol, suggesting that the magnitude of the T2D risk could be reduced in male workers if lifestyle modifications related to tobacco and alcohol use were undertaken. ${ }^{17,18}$ Sulphur dioxide exposure was found to be associated with
Table 4. The baseline levels of clinical laboratory-based tests of the participants in the Jinchang Cohort Study (mean \pm standard deviation)

\begin{tabular}{|c|c|c|c|}
\hline Variables & Male & Female & Total \\
\hline \multicolumn{4}{|l|}{ Haematological traits } \\
\hline WBC (10 9/1) & $6.6(1.7)$ & $5.7(1.5)$ & $6.2(1.7)$ \\
\hline $\operatorname{RBC}(1012 / 1)$ & $5.2(0.4)$ & $4.6(0.4)$ & $5(0.5)$ \\
\hline $\operatorname{PLT}(109 / 1)$ & $166.6(47.5)$ & $188.6(51.7)$ & $175.1(50.3)$ \\
\hline Haemoglobin (g/l) & $158.6(10.5)$ & $136.5(12.2)$ & $150.1(15.5)$ \\
\hline $\mathrm{FBG}(\mathrm{mmol} / \mathrm{l})$ & $5.5(1.5)$ & $5.2(1.2)$ & $5.4(1.4)$ \\
\hline \multicolumn{4}{|l|}{ Hepatic function } \\
\hline $\operatorname{ALT}(\mathrm{U} / \mathrm{l})$ & $39.7(32.7)$ & $25.8(21.4)$ & $34.4(29.6)$ \\
\hline $\operatorname{AST}(\mathrm{U} / \mathrm{l})$ & $37.0(22)$ & $31.9(16)$ & $35.0(20.1)$ \\
\hline $\operatorname{ALP}(\mathrm{U} / \mathrm{l})$ & $71.8(20.7)$ & $63(22.9)$ & $68.5(21.9)$ \\
\hline GGT (U/l) & $45.4(63)$ & $24.5(34.4)$ & $37.5(55)$ \\
\hline Total bilirubin $(\mu \mathrm{mol} / \mathrm{l})$ & $17.2(7.1)$ & $15(5.5)$ & $16.3(6.6)$ \\
\hline Direct bilirubin $(\mu \mathrm{mol} / \mathrm{l})$ & $4.9(2.9)$ & $3.4(1.9)$ & $4.3(2.6)$ \\
\hline Indirect bilirubin $(\mu \mathrm{mol} / \mathrm{l})$ & $12.3(5)$ & $11.6(4.2)$ & $12(4.7)$ \\
\hline \multicolumn{4}{|l|}{ Renal function } \\
\hline BUN (mmol/l) & $5.7(1.5)$ & $5(1.4)$ & $5.4(1.5)$ \\
\hline Serum Creatinine $(\mu \mathrm{mol} / \mathrm{l})$ & $77.3(17.6)$ & $60(12.6)$ & $70.7(18)$ \\
\hline Uric Acid $(\mu \mathrm{mol} / \mathrm{l})$ & $361.5(74.7)$ & 270.8 & $327.3(82.1)$ \\
\hline \multicolumn{4}{|l|}{ Lipids } \\
\hline TC (mmol/l) & $4.7(0.9)$ & $4.8(0.9)$ & $4.7(0.9)$ \\
\hline $\mathrm{TG}(\mathrm{mmol} / \mathrm{l})$ & $2.2(1.7)$ & $1.6(1.1)$ & $1.9(1.5)$ \\
\hline HDL-C (mmol/l) & $1.3(0.3)$ & $1.5(0.4)$ & $1.4(0.4)$ \\
\hline LHL-C (mmol/l) & $3(0.7)$ & $3.1(0.8)$ & $3.1(0.8)$ \\
\hline
\end{tabular}

earlier mean age at natural menopause in non-office workers in the cohort. ${ }^{16}$ Reproductive factors such as age at menarche, age at menopause and reproductive life span, were associated with increased risk of T2D in women of the cohort. ${ }^{22}$ By case-control study, we also observed that MetS was associated with an elevated risk of breast cancer among postmenopausal women in the cohort. ${ }^{21}$

Two additional articles addressing molecular mechanisms underlying cancer pathogenesis have also been published. ${ }^{23,24}$ We measured H3k4me3 and H3D27 trimethylation levels in 280 subjects' blood cells. H3K4me3 levels were found to be higher in nickel smelting workers $(47.24 \pm 20.85)$ than in office workers $(22.65 \pm$ $8.81 ; P=0.000)$, whereas the opposite was found for levels of H3K27me3 $(13.88 \pm 4.23$ vs $20.67 \pm 5.96, P=$ $0.000)$, indicating that occupational exposure to nickel was associated with alterations in levels of histone modification. Compared with office workers, nickel smelting workers had higher levels of 8-OhdG and lower levels of hOGG1. We also observed that DNA damage was increased with employment duration and was related to the inhibition of hOGG1 repair capacity among smelting workers of the cohort.

Biomonitoring of metals in urine is an important tool to assess the levels of metal exposure. We observed the higher 
Table 5. Urinary metal levels (ug/l) in workers of the Jinchang Cohort $(N=500)$ and other reported general populations

\begin{tabular}{|c|c|c|c|c|c|c|c|}
\hline \multirow[t]{2}{*}{ Metal } & \multicolumn{4}{|c|}{ Selected percentiles } & \multirow[t]{2}{*}{ Median } & \multirow[t]{2}{*}{ Feng et al. $2015^{\mathrm{a}}$} & \multirow{2}{*}{$\begin{array}{l}\text { USCDC, } 2015^{\mathrm{b}} / \\
\text { Canada H. } 2010^{\circ}\end{array}$} \\
\hline & 5 th & 25 th & 75 th & 95th & & & \\
\hline Arsenic (As) & 19.55 & 38.66 & 123.46 & 505.97 & 65.16 & 28.43 & $6.09 / 11.67$ \\
\hline Cadmium (Cd) & 0.24 & 0.43 & 1.17 & 2.68 & 0.68 & 0.89 & $0.19 / 0.38$ \\
\hline Cobalt (Co) & 0.25 & 0.47 & 1.21 & 3.07 & 0.68 & 0.24 & $0.308^{c}$ \\
\hline Copper $(\mathrm{Cu})$ & 8.49 & 12.25 & 22.11 & 37.12 & 16.60 & 7.4 & $9.99^{c}$ \\
\hline Nickel (Ni) & 1.95 & 3.44 & 9.21 & 22.19 & 5.39 & 2.26 & $1.16^{\mathrm{c}}$ \\
\hline $\operatorname{Zinc}(\mathrm{Zn})$ & 94.89 & 216.19 & 581.03 & 1014.62 & 359.21 & 270.49 & $274.33^{c}$ \\
\hline
\end{tabular}

${ }^{a}$ Chinese general population (aged 18-80 years) in Wuhan City (2011), $N=2242$.

${ }^{b}$ US general population ( $\geq 20$ years, $N=2329$ ), Fourth National Report on Human Exposure to Environmental Chemicals. Dekalb County, GA: Centers for Disease Control and Prevention, 2015.

${ }^{\mathrm{c}}$ Canadian general population (6-79 years, $N=5$ 319), Statistics Canada, Report on Human Exposure to Environmental Chemicals in Canada, (2001-2009). Ottawa, ON: Statistics Canada, 2009.

urinary levels of metal among 500 urine samples in the Jinchang Cohort by using inductively coupled plasma mass spectrometry (ICP-MS). As seen in Table 5, urinary levels of metals for workers in the cohort were higher than reported among the general population. ${ }^{25,26}$ The median levels of urinary nickel, cobalt, copper, zinc, cadmium and arsenic were $5.39 \mu \mathrm{g} / \mathrm{l}, 0.68 \mu \mathrm{g} / \mathrm{l}, 16.60 \mu \mathrm{g} / \mathrm{l}, 359.21 \mu \mathrm{g} / \mathrm{l}$, $0.68 \mu \mathrm{g} / \mathrm{l}$ and $65.16 \mu \mathrm{g} / \mathrm{l}$, respectively. Many of these metals are considered as definite or possible carcinogens, ${ }^{7}$ and growing epidemiological evidence has highlighted the link of heavy metal to chronic diseases such as diabetes and obesity. ${ }^{9}$ We will address the associations between multiple metal exposures and risk of diabetes and other health effects in future studies with the platform of the Jinchang Cohort Study.

\section{What are the main strengths and weaknesses?}

The Jinchang Cohort Study has several strengths. The main strengths are the unique exposure of the cohort population and the scheduled follow-up of each participant every 2 years with a repeated medical examination to update exposure and outcome information. Second, the location of the workers of the cohort is stable, and this will minimize loss to follow-up. Third, the large dataset from the comprehensive epidemiological survey and medical examinations will permit extensive evaluation of the relationships between multiple metal exposures, gene, epigenetics and risk of human diseases. Finally, the large number of repository biospecimens will provide a populationbased platform to examine biological indicators that closely correlate with multiple metal exposures and illness, by using molecular epidemiological methods.

The main limitation of this cohort study is that the data of metal levels in air were not collected at the baseline survey; information on workplace exposures was not available. However, in 2016 the cohort plans to collaborate with the company to monitor metal levels in workplace. This would allow the study of dose-response relationships between multiple metal exposures and human health effects. Additionally, the healthy-worker effect needs to be kept in mind when interpreting the results in this occupational study. ${ }^{27}$ The scheduled follow-up of the cohort, particularly repeated measures of exposure and health outcome, can minimize the healthy -worker effect bias. Analyses that involve internal reference comparisons among cohort subgroups, as in dose-response estimation, can also minimize the bias.

\section{Can I get hold of the data? Where can I find out more?}

The Jinchang Cohort Study welcomes researchers interested in collaboration. We request a short research proposal including information on the background, research questions and methods, timetable and budget, and authorship. For more information contact the corresponding author of this paper, Yana Bai [baiyana@lzu.edu.cn], or Tongzhang Zheng [tongzhang_zheng@brown.edu].

\section{Jinchang Cohort profile in a nutshell}

- The Jinchang Cohort Study is a prospective cohort with unique metal exposures of an occupational population to extensively evaluate multiple metals, psychological, biological, genetic, epigenetic and other occupational exposures in relation to a diverse range of health effects.

- A total of 42122 workers aged $\geq 20$ years were recruited at baseline between 2011 and 2013 in a 
nonferrous metal company, Jinchang city, China.

- Follow-up has been scheduled once every 2 years with a repeated medical examination to update exposure and outcome information. By December 2015, 37 040 workers had completed the first follow-up.

- The dataset comprises a wide range of epidemiological survey, comprehensive physical examination, clinical laboratory-based tests, biological samples and linkage to health records.

- Collaborations are encouraged. Any researcher interested in exploring Jinchang Cohort data should directly contact Yana Bai [baiyana@lzu.edu.cn], or Tongzhang Zheng [tongzhang_zheng@brown.edu].

\section{Funding}

This work is supported by the Project of Employees Health Status and Disease Burden Trend Study in Jinchuan Nonferrous Metals Corporation (Grant JKB20120013). Also, this work is partly supported by Fogarty training grants D43TW 008323 and D43TW007864-01 from the US National Institutes of Health. A.Y. is also partially supported by the China Scholarship Council (CSC).

\section{Acknowledgements}

We thank all study participants and staff of the Worker's Hospital of the JNMC for their generous work, and the interviewers from the Department of Epidemiology and Health Statistics, School of Public Health, Lanzhou University. We also thank D. Simin Liu from Brown University for put into writing and revising the manuscript.

Conflict of interest: None declared.

\section{References}

1. Liu J, Diamond J. China's environment in a globalizing world. Nature 2005;435:1179-86.

2. US Geological Survey. Historical Statistics for Mineral and Material Commodities in the United States. Reston, VA: US Geological Survey, 2014.

3. Wild CP. Environmental exposure measurement in cancer epidemiology. Mutagenesis. 2009;24:117-25.

4. IARC. Nickel and Nickel Compounds. Lyon, France: International Agency for Research on Cancer, 2009.

5. IARC. Chromium, Nickel and Welding. Monographs on the Evaluation of Carcinogenic Risks to Humans. Lyon, France: International Agency for Research on Cancer, 1990.

6. Kim HS, Kim YJ, Seo YR. An overview of carcinogenic heavy metal: molecular toxicity mechanism and prevention. J Cancer Prev 2015;20:232.

7. IARC (International Agency for Research on Cancer). Arsenic, Metals, Fibres and Dusts, Monographs on the evaluation of carcinogenic risks to humans, Volume 100C (2012) 2014. Available from: http://monographs.iarc.fr/ENG/Monographs/vol100C/index.php.

8. Kuo C-C, Moon K, Thayer KA, Navas-Acien A. Environmental chemicals and type 2 diabetes: an updated systematic review of the epidemiologic evidence. Curr Diabetes Rep 2013;13: 831-49.

9. Kuo C-C, Navas-Acien A. Commentary: Environmental chemicals and diabetes: which ones are we missing? Int J Epidemiol 2015;44:248-50.

10. China Diabetes Society. [Suggestions about metabolic syndrome of Chinese diabetes society.] Chin J Diabetes 2004;12:156-61.

11. Perloff D, Grim C, Flack J et al. Human blood pressure determination by sphygmomanometry. Circulation 1993;88:2460-70.

12. Li M, Na BY, Quan PH et al. A retrospective cohort mortality study in Jinchang, the largest nickel production enterprise in China. Biomed Environ Sci 2014;27:567-71.

13. Qu H, Bai Y, Cheng $\mathrm{N}$ et al. Trend analysis of cancer mortality in the Jinchang Cohort, China, 2001-2010. Biomed Environ Sci. 2015;28:364-69.

14. Cameron KS, Buchner V, Tchounwou PB. Exploring the molecular mechanisms of nickel-induced genotoxicity and carcinogenicity: a literature review. Rev Environ Health 2011;26:81-92.

15. Bai YN, Yang AM, Pu HQ et al. Nickel-exposed workers in China: A cohort study. Biomed Environ Sci 2014;27:208-11.

16. Wang D, Wang M, Cheng $\mathrm{N}$ et al. Sulfur dioxide exposure and other factors affecting age at natural menopause in the Jinchuan cohort. Climacteric 2015;8:722-32.

17. Yang AM, Liu S, Cheng N et al. Multiple Metals Exposure, Elevated Blood Glucose and Dysglycemia among Chinese Occupational Workers. J Diabetes Complications 2016, July 27. DOI: $10.1016 /$ j.jdiacomp.2016.07.022

18. Yang AM, Cheng N, Pu HQ et al. Occupational metal exposures, smoking and risk of diabetes and prediabetes. Occup Med (Lond) 2016, Jul 14. pii: kqw078. [Epub ahead of print.]

19. Yang AM, Cheng N, Pu HQ et al. Metal exposure and risk of diabetes and prediabetes among Chinese occupational workers. Biomed Environ Sci 2015;28:875-83.

20. Yang AM, Bai YN, Pu HQ et al. Prevalence of metabolic syndrome in Chinese nickel-exposed workers. Biomed Environ Sci 2014;27:475-77.

21. Wang M, Cheng N, Zheng S et al. Metabolic syndrome and the risk of breast cancer among postmenopausal women in northwest China. Climacteric 2015;18:852-58.

22. Yang A, Liu S, Cheng N et al. Reproductive factors and risk of type 2 diabetes in an occupational cohort of Chinese women. $J$ Diabetes Complications 2016, Jun 14. pii: S10568727(16)30212-4. [Epub ahead of print.]

23. Ma L, Bai Y, Pu H et al. Histone methylation in nickel-smelting industrial workers. PloS One 2015;10:e0140339.

24. Shan W, Bai YN, Pu HQ et al. Dynamic changes in DNA damage and repair biomarkers with employment length among nickel smelting workers. Biomed Environ Sci 2015;28:679-82.

25. Feng W, Cui X, Liu B et al. Association of urinary metal profiles with altered glucose levels and diabetes risk: a population-based study in China. PloS One 2015;10:e123742.

26. Goullé J-P, Mahieu L, Castermant J et al. Metal and metalloid multi-elementary ICP-MS validation in whole blood, plasma, urine and hair: Reference values. Forensic Sci Int 2005;153: 39-44.

27. Sterling TD, Weinkam JJ. The 'healthy worker effect'on morbidity rates. J Occup Environ Med 1985;27:477-82. 